\title{
Novamente a questão do aborto no Brasil: ventos de mudança?
}

\author{
Again the issue of abortion in Brazil: winds of change?
}

\section{Editorial}

É extremamente oportuna a discussão acerca do aborto trazida pelo trabalho de Borsari et al. ${ }^{1}$, publicado no presente número da Revista Brasileira de Ginecologia e Obstetrícia (RBGO). As discussões sobre o tema parecem ter ganhado merecido destaque recentemente. Em abril deste ano a decisão do Supremo Tribunal Federal (STF) por dois votos contrários e oito votos em favor da não criminalização do abortamento de fetos anencéfalos forçou o debate sobre a descriminalização do aborto para além das cúpulas da Câmara e do Senado Federal. Com essa decisão, nesses casos a mulher não precisará mais de uma autorização judicial para a interrupção da gravidez, e isso pode ajudar a criar um novo paradigma jurídico e legislativo sobre a saúde da mulher no Brasil.

Essa votação não envolveu apenas questões médicas e jurídicas, mas trouxe à tona toda uma discussão sobre autonomia das mulheres e direitos reprodutivos que vêm sendo pauta de reivindicação de grupos organizados de mulheres e objeto de estudos científicos no país há algum tempo ${ }^{2,3}$. No entanto, a ampliação dos direitos legais sobre as liberdades reprodutivas, em específico sobre as questões relacionadas ao aborto, não ocorre senão sem retrocessos.

Nesses anos todos vários projetos favoráveis à descriminalização do abortamento foram apreciados pelo Congresso Nacional, sem que nenhum tivesse sido finalmente encaminhado ao Plenário. No ano de 2011 houve até comemoração por parte de um grupo de parlamentares pelo arquivamento do Projeto de Lei n ${ }^{\circ}$ 1.135/91, tramitado desde 1991 na Câmara dos Deputados, que propunha a supressão do artigo do Código Penal que caracteriza como crime o aborto provocado pela gestante ou com seu consentimento ${ }^{4}$. Além disso, ainda tramitam no Congresso Nacional projetos que visam restringir ainda mais as práticas legais de aborto 5 .

No entanto, parece que a recente decisão do STF tem pressionado o Poder Legislativo a não mais evitar uma decisão sobre o assunto. A proposição do anteprojeto de código penal pela comissão de juristas criada pelo Senado trouxe mais um indicativo de que há suficiente pressão social para mudanças na legislação sobre aborto no Brasil. A necessidade de mudança já era clara nas falas de juízes e promotores desde 2006. Um estudo realizado com mais de 4.000 juristas no Brasil (ente juízes e promotores) observou que nos anos de 2005 e 2006 quase $80 \%$ dos participantes acreditavam que as circunstâncias de não criminalização do aborto deveriam ser ampliadas, ou mesmo que o aborto não deveria ser considerado crime, independentemente da circunstância em que fosse praticado ${ }^{6}$.

Correspondência Rodovia Washington Lús, km 235 - SP-310 (EP: $13565-905$ São Carlos (SP), Brasil Recebido $20 / 11 / 2012$ Aceito com modificações $04 / 12 / 2012$
'Departamento de Medicina, Universidade Federal de São Carlos - UFSCar - São Carlos (SP), Brasil. 
$\mathrm{O}$ atual anteprojeto que se encontra em discussão no Senado amplia as condições em que o abortamento pode ser realizado. Além das situações atualmente permitidas, essa proposta considera não haver crime de aborto na interrupção consentida da gravidez quando esta resultar do emprego não autorizado de técnica de reprodução assistida, em casos de anencefalia ou de condições patológicas fetais não compatíveis com a vida extrauterina, ou mesmo até a décima segunda semana de gestação se por vontade da gestante e mediante constatação, por médico ou psicólogo, de que a mulher não apresenta condições psicológicas de arcar com a maternidade ${ }^{7}$.

Mesmo considerando as fragilidades dessa proposta, há de se reconhecer que existe uma mudança na posição dos legisladores sobre o tema. Essa é uma discussão nada simples e envolve, além de questões médicas e jurídicas, considerações éticas, religiosas e morais. Contudo, apenas $10 \%$ dos católicos brasileiros acreditam que os ensinamentos da Igreja Católica devam prevalecer sobre a diversidade de opiniões que existe no país ${ }^{8}$. E, todavia, um estado laico como o brasileiro não deve pautar suas leis em preceitos morais e religiosos, mas em dados e fatos sociais relevantes.

Essa talvez seja a contribuição mais importante que o presente número da RBGO traz em um de seus artigos ${ }^{1}$. No estudo intitulado "Aborto provocado em mulheres da periferia da cidade de São Paulo: vivência e aspectos socioeconômicos", os autores (em sua maioria mulheres) apresentam a dura realidade das mulheres que admitem terem realizado aborto: a vulnerabilidade social. $\mathrm{O}$ artigo mostra que aquelas internadas por aborto provocado possuíam escolaridade mais baixa e renda quase $30 \%$ menor que o grupo de mulheres internadas por aborto espontâneo.

De fato, é a vulnerabilidade social que coloca essas mulheres em maior risco de um aborto inseguro. Embora haja poucos estudos, sabe-se que mulheres com melhor renda têm um sistema mais acessível e menos inseguro para a prática do aborto, ainda que clandestino e ilegal. Então, não é a clandestinidade o problema, mas a vulnerabilidade. Por isso o aborto mata mulheres pobres.

E isso é o que indiretamente é reforçado no estudo de Borsari et al. ${ }^{1}$, quando aponta a associação entre renda e escolaridade baixas e aborto provocado. Em geral são mulheres não brancas, pobres, migrantes, com baixa escolaridade, solteiras e não usuárias de método contraceptivo que se submetem ao aborto inseguro ${ }^{9-11}$. E são justamente essas mulheres em situação de vulnerabilidade, impactadas pela desigualdade social, desigualdade de gênero e pelo racismo, que têm maior risco de complicações decorrentes do aborto. Tanto o risco de morte quanto o risco de morbidade materna grave estão aumentados nos casos de aborto, sobretudo se inseguro.

No Brasil, dados oriundos da Pesquisa Nacional de Demografia e Saúde (PNDS) comprovam essa hipótese. Complicações obstétricas em geral são mais prevalentes em situações de aborto. Em especial as complicações hemorrágicas e infecciosas são duas vezes mais frequentes em gestações que terminaram em aborto do que entre aquelas que terminaram em parto ${ }^{12,13}$. Além disso, estima-se que cerca de $5 \%$ das mulheres com complicações graves relacionadas ao aborto evoluem com disfunção orgânica grave, à condição agora conhecida como near miss materno. Embora quando comparado com outras causas o aborto responda por pequena porcentagem dos casos de morbidade materna grave, quando as complicações são decorrentes de aborto evoluem com mais frequência para situações graves ${ }^{13}$.

Isso decorre menos de questões biológicas do que da falta de assistência adequada. Demoras na assistência obstétrica em qualquer nível de atenção associam-se com a gravidade das complicações do aborto ${ }^{13}$. E no que tange à falta de acesso à saúde, a dificuldade vai além da disponibilidade dos serviços de assistência, esbarrando na falta de qualificação dos existentes. É o que mostra estudo recente que avalia a qualidade do atendimento ao aborto no SUS ${ }^{14}$. A atenção ao aborto em geral está distante do que propõem as normas brasileiras, em especial a Norma Técnica de Atenção Humanizada ao Abortamento publicada há sete anos ${ }^{15}$. As mulheres sofrem desde a dificuldade de acesso a uma vaga até discriminação por parte dos profissionais.

A condição de ilegalidade induz a um julgamento velado das mulheres pelos profissionais que as assistem, o que compromete o atendimento à medida que nem mesmo o alívio da dor antes do procedimento de curetagem é rotina nos serviços estudados ${ }^{14}$. Em geral, os atendimentos às mulheres em situação de abortamento parecem correlacionar-se positivamente com os procedimentos técnicos e negativamente com cuidado integral, evidenciado pela grande carência na continuidade dos cuidados, seja no planejamento reprodutivo pós-abortamento, seja no agendamento das consultas de revisão — elementos essenciais segundo a norma do Ministério da Saúde ${ }^{15}$.

Essa condição influi negativamente até mesmo no atendimento aos casos permitidos por lei, seja pela escassez de serviços, seja pelo conhecimento precário dos profissionais de saúde acerca do tema. Hoje o Brasil conta com 65 instituições cadastradas para a realização de aborto legal, número pequeno para o tamanho da população, mas até 2005 eram apenas 37 e concentradas principalmente nas regiões Sul e Sudeste ${ }^{8}$. Sobre o conhecimento dos profissionais, embora tenha havido mudança nas concepções, de uma visão mais moralista em direção à promoção da autonomia das mulheres, o conhecimento sobre as leis ainda é pequeno ${ }^{16-18}$. Mesmo entre estudantes de Medicina, o atual conhecimento sobre aborto é questionável. Embora os alunos do último ano do curso de Medicina já tenham ouvido falar de 
misoprostol para a interrupção da gravidez, poucos têm conhecimento para aplicá-lo ${ }^{19}$. Todavia, um recente estudo indica que estudantes de Medicina e Direito parecem ter melhor conhecimento sobre as condições legais atualmente permitidas para o aborto e tendem a se mostrar favoráveis à ampliação legal do aborto em outras situações ${ }^{20}$.

O estudo de Borsari et al. ${ }^{1}$ mostra, ainda, que os sentimentos negativos expressados pelas mulheres estão presentes desde a suspeita da gravidez, em maior frequência no grupo de aborto provocado. Isso aponta para outro problema importante e intrinsecamente associado ao aborto: a gestação indesejada. O aborto passa a ser consequência inevitável de uma história de alternativas escassas em opções reprodutivas. E, assim como a própria gravidez indesejada, a decisão pelo aborto não é inócua e leva consigo sofrimento físico e emocional.

Embora no Brasil tenha havido melhoria no acesso a alguns métodos contraceptivos pelas mulheres menos favorecidas economicamente - em especial no acesso à esterilização feminina, houve pouca mudança na diversidade da contracepção utilizada por mulheres com pior nível socioeconômico. Segundo a PNDS de 2006, a utilização de métodos pela camada mais baixa da população concentra-se na esterilização feminina e na pílula, sendo que $26 \%$ das mulheres unidas entre 15 e 44 anos não usam nenhum método ${ }^{21}$.

Mas em um contexto de opções reprodutivas restritas e proibição legal do aborto, resta a essas mulheres a clandestinidade. No contexto excludente de um sistema de saúde ineficaz, a ilegalidade e a clandestinidade estão, sim, associadas a procedimentos inseguros e à demora no atendimento.

O aborto inseguro é expressão da falta de acesso. Uma evidência da falha no sistema social que começa na (falta de) educação, suporte social, passa pelo acesso restrito à saúde, pelo acesso limitado a bens de consumo e, como consequência, restrição das perspectivas de vida. O aborto, então, impõe-se dentro das parcas possibilidades como uma escolha que, assim como outras, implicará grandes obstáculos a serem transpostos pelas mulheres que o vivenciam.

Recente artigo que avalia a mortalidade materna no Chile por meio de uma série temporal concluiu que a redução da razão de mortalidade materna (RMM) não está relacionada com o status legal do aborto ${ }^{22}$. Esse país adota uma política fortemente restritiva com relação ao aborto, incluindo proibição ao aborto terapêutico, e os autores afirmam que essa política não aumentou a mortalidade materna; ao contrário, a RMM caiu quase 70\% em 14 anos após a proibição do aborto. Mas tal afirmação beira a falácia ecológica! Ao longo dos anos nesse mesmo país houve um grande incremento em educação e renda da população e na qualificação da assistência médica prestada à saúde da mulher, o que inclui programas exitosos de contracepção.

Independentemente da questão legal do aborto, o que de fato importa é a melhoria no acesso e a qualificação da assistência à saúde materna. As estratégias para a prevenção do abortamento inseguro e consequentemente das mortes relacionadas ao aborto são conhecidas e envolvem ações sistêmicas em todos os níveis de prevenção: redução da gestação indesejada, assistência médica de qualidade ao abortamento, reconhecimento e manejo adequado das complicações decorrentes do aborto e planejamento familiar pós-aborto 23 . O que falta é implementar tais ações.

Nos últimos dois anos este é o terceiro editorial ${ }^{24,25}$ sobre aborto acompanhando estudos a respeito do tema publicados na RBGO. A preocupação desta revista em trazer luz a essa discussão está em consonância com o momento social de pressão para mudanças mais significativas nesse quadro. E nada mais adequado que isso seja discutido nesta revista — afinal, é nas mãos de ginecologistas e obstetras que a tragédia do aborto inseguro termina. Talvez seja a hora oportuna de terminarmos com isso.

\section{AGRADECIMENTOS}

Ao Dr. José Guilherme Cecatti pelos comentários em versões preliminares deste artigo.

\section{Referências}

1. Borsari C, Nomura R, Benute G, de Lucia M, Francisco R, Zugaib M. [Abortion in women living in the outskirts of Sao Paulo: experience and socioeconomic aspects]. Rev Bras Ginecol Obstet. 2013;35(1):27-32. Portuguese.

2. Menezes G, Aquino EML. Pesquisa sobre o aborto no Brasil: avanços e desafios para o campo da saúde coletiva. Cad Saúde Pública. 2009;25 Supl 2:S193-S204.

3. Diniz D, Corrêa M, Squinca F, Braga KS. Aborto: 20 anos de pesquisas no Brasil. Cad Saúde Pública. 2009;25(4):939-42.

4. Câmara dos Deputados. Frente comemora arquivamento de projeto que descriminalizaria o aborto. Agência Câmara de Notícias. 2011 [citado 2012 Nov 16]. Disponível em: <http://www2.camara.leg.br/agencia/noticias/saude/196106-frente-comemora-arquivamento-deprojeto-que-descriminalizaria-o-aborto.htmls 
5. Câmara dos Deputados. Rejeitados quatro projetos que caracterizam aborto como crime hediondo. Agência Câmara de Notícias. 2011 [citado 2012 Nov 16]. Disponível em: <http://www2.camara.leg.br/agencia/noticias/direito-e-justica/203235-rejeitados-quatro-projetosque-caracterizam-aborto-como-crime-hediondo.html>

6. Duarte GA, Osis MD, Faúndes A, Sousa MH. Aborto e legislação: opinião de magistrados e promotores de justiça brasileiros. Rev Saúde Pública. 2010;44(3):406-20.

7. Comissão de Juristas para a Elaboração de Anteprojeto de Código Penal. Relatório final. 2012 [citado 2012 Nov 16]. Disponível em: <http://www.ibccrim.org.br/upload/noticias/pdf/projeto.pdf>

8. Talib RA, Citeli MT. Serviços de aborto legal em hospitais públicos brasileiros (1989-2004). São Paulo: Católicas pelo Direito de Decidir; 2005.

9. Silva RS, Vieira EM. Frequency and characteristics of induced abortion among married and single women in São Paulo, Brazil. Cad Saúde Pública. 2009;25(1):179-87.

10. Fonseca W, Misago C, Freitas P, Santos E, Fernandes L, Correia L. Características sócio-demográficas, reprodutivas e médicas de mulheres admitidas por aborto em hospital da Região Sul do Brasil. Cad Saúde Pública. 1998;14(2):279-86.

11. Fusco CLB, Andreoni S, Silva RS. Epidemiologia do aborto inseguro em uma população em situação de pobreza - Favela Inajar de Souza, São Paulo. Rev Bras Epidemiol. 2008; 11 (1):78-88.

12. Camargo RS, Santana DS, Cecatti JG, Pacagnella RC, Tedesco RP, Melo EF Jr, et al. Severe maternal morbidity and factors associated with the occurrence of abortion in Brazil. Int J Gynaecol Obstet. 2011;112(2):88-92.

13. Santana DS, Cecatti JG, Parpinelli MA, Haddad SM, Costa ML, Sousa MH, et al. Severe maternal morbidity due to abortion prospectively identified in a surveillance network in Brazil. Int J Gynaecol Obstet. 2012;1 19(1):44-8.

14. Aquino EML, Menezes G, Barreto-de-Araújo TV, Alves MT, Alves SV, Almeida MCC, et al. Qualidade da atenção ao aborto no Sistema Único de Saúde do Nordeste brasileiro: o que dizem as mulheres? Ciênc Saúde Coletiva. 2012;17(7):1765-76.

15. Brasil. Ministério da Saúde. Secretaria de Atenção à Saúde. Departamento de Ações Programáticas Estratégicas. Área Técnica de Saúde da Mulher. Atenção humanizada ao abortamento: norma técnica. Brasília (DF): Ministério da Saúde; 2005.

16. Faúndes A, Duarte GA, Osis MD, Andalaft Neto J. [Knowledge and opinion variations of Brazilian obstetricians and gynecologists face to legal abortion, between 2003 and 2005]. Rev Bras Ginecol Obstet. 2007;29(4): 192-9. Portuguese.

17. Loureiro DC, Vieira EM. Aborto: conhecimento e opinião de médicos dos serviços de emergência de Ribeirão Preto, São Paulo, Brasil, sobre aspectos éticos e legais. Cad Saúde Pública. 2004;20(3):679-88.

18. Soares GS. Profissionais de saúde frente ao aborto legal no Brasil: desafios, conflitos e significados. Cad Saúde Pública. 2003;19 Supl 2:S399-S406.

19. Fernandes KG, Camargo RP, Duarte GA, Faúndes A, Sousa MH, Maia Filho NL, et al. Knowledge of medical abortion among Brazilian medical students. Int J Gynaecol Obstet. 2012;118 Suppl 1:S10-4.

20. Medeiros RD, Azevedo GD, Oliveira EAA, Araújo FA, Cavalcanti FJB, Araújo GL, et al. Opinião de estudantes dos cursos de Direito e Medicina da Universidade Federal do Rio Grande do Norte sobre o aborto no Brasil. Rev Bras Ginecol Obstet. 2012;34(1):16-21.

21. Brasil. Ministério da Saúde. Secretaria de Ciência, Tecnologia e Insumos Estratégicos. Departamento de Ciência e Tecnologia. PNDS 2006: Pesquisa Nacional de Demografia e Saúde da Criança e da Mulher. Brasília (DF): Ministério da Saúde; 2008.

22. Koch E, Thorp J, Bravo M, Gatica S, Romero CX, Aguilera H, et al. Women's education level, maternal health facilities, abortion legislation and maternal deaths: a natural experiment in Chile from 1957 to 2007. PloS ONE. 2012;7(5):e36613.

23. Faúndes A. Strategies for the prevention of unsafe abortion. International journal of Gynaecology and Obstetrics. Int J Gynaecol Obstet. 2012;119 Suppl 1:S68-71.

24. Vieira EM. [The question of abortion in Brazil]. Rev Bras Ginecol Obstet. 2010;32(3):103-4. Portuguese.

25. Vieira EM. [Legal abortion: knowledge of the professionals and implications of public policies]. Rev Bras Ginecol Obstet. 2012;34(1):1-3. Portuguese. 